\title{
Multilevel analyses of neighbourhood socioeconomic context and health outcomes: a critical review
}

\author{
K E Pickett, M Pearl
}

\begin{abstract}
Purpose-Interest in the effects of neighbourhood or local area social characteristics on health has increased in recent years, but to date the existing evidence has not been systematically reviewed. Multilevel or contextual analyses of social factors and health represent a possible reconciliation between two divergent epidemiological paradigms-individual risk factor epidemiology and an ecological approach.
\end{abstract}

Data sources-Keyword searching of Index Medicus (Medline) and additional references from retrieved articles.

Study selection-All original studies of the effect of local area social characteristics on individual health outcomes, adjusted for individual socioeconomic status, published in English before 1 June 1998 and focused on populations in developed countries.

Data synthesis-The methodological challenges posed by the design and interpretation of multilevel studies of local area effects are discussed and results summarised with reference to type of health outcome. All but two of the 25 reviewed studies reported a statistically significant association between at least one measure of social environment and a health outcome (contextual effect), after adjusting for individual level socioeconomic status (compositional effect). Contextual effects were generally modest and much smaller than compositional effects. Conclusions-The evidence for modest neighbourhood effects on health is fairly consistent despite heterogeneity of study designs, substitution of local area measures for neighbourhood measures and probable measurement error. By drawing public health attention to the health risks associated with the social structure and ecology of neighbourhoods, innovative approaches to community level interventions may ensue.

(F Epidemiol Community Health 2001;55:111-122)

and Community

Medicine, University

of California, San

Francisco

M Pearl

Correspondence to:

Dr Pickett

(kpickett@

health.bsd.uchicago.edu)

Accepted for publication 28 August 2000 economic status, the most advantaged have better health status than the less advantaged. ${ }^{3}$

Population inequalities in disease are not generally accounted for by any known combination of individual genetic and environmental risk factors, and must therefore be attributable to other unmeasured factors, some of which may operate at an aggregate level (see various publications $^{24-11}$ for discussions). Winkelstein has pointed out that "ecological factors may be the most important determinants of the health and disease status of a population". ${ }^{12}$ The neighbourhoods in which people live may influence health, operating through such mechanisms as: the availability and accessibility of health services; infrastructure deprivation (lack of parks, stores selling healthy foods at affordable prices, etc); the prevalence of prevailing attitudes towards health and health related behaviours; and stress and a lack of social support. ${ }^{8}$

Although there is an established tradition of inquiry into the impact of neighbourhood factors on sociological outcomes, such as educational attainment and labour market opportunities, ${ }^{13-15}$ neighbourhood variation in health has received less attention in epidemiology until recently. In part this is because of the intractability of the ecological fallacy when group level data are used to infer individual disease risk, and also because of a disciplinary focus on individual risk factors through much of this century. ${ }^{916}$ An increasing interest in societal influences on individual health status, along with improved statistical techniques for combining group level and individual level factors in regression models has spurred interest in contextual research in epidemiology. ${ }^{6}$

The statistical issues involved in multilevel studies have been well described, ${ }^{17}$ and hierarchical regression analysis is becoming widely accepted as the appropriate tool for examining group level effects on individual health. To date, there has been no published summary of the results of multilevel epidemiological studies and the literature reviews included with most published analyses have been incomplete. The validity and generalisability of neighbourhood effects remain open to question, and as yet there has been little empirical investigation of the causal pathways by which social environments translate into biological states of health and disease. Indeed, it is probable that neighbourhood or contextual effects will themselves be contextual, and that both the factors themselves and the magnitude of their effects will be context dependent. In this paper we 
seek to summarise the epidemiological literature, paying particular attention to methodological issues inherent in multilevel studies, so that the literature can be viewed in its entirety.

\section{Methods}

Studies were identified via keyword searching on Medline using the terms multi-level, social class, neighborhood, socioeconomic factors, health outcomes, and additional studies were retrieved from reference lists. Inclusion criteria for studies were: (1) published in English in peer reviewed journals before June 1998, (2) study population in a developed country, (3) outcome of physical or mental health or health behaviour, measured at the individual level, (4) multilevel studies with socioeconomic information measured at both the individual level and area level. There is a large body of literature from the sociological and demographic literature covering community effects on fertility and sexual behaviour that is not covered in this review (see for example Brews$\operatorname{ter}^{18}$ and Grady et $a l^{19}$ ). The growing epidemiological literature on income inequality (see for example ${ }^{20-23}$ ) that is concerned with estimating the effect of differentials in socioeconomic status rather than the effect of low socioeconomic status in itself is also excluded, as it has methodological issues deserving of separate treatment.

We identified 25 studies using these criteria (table 1). We categorised results by health outcome: mortality, morbidity (only one study examined mental health) and health behaviours. Five studies had results in more than one category and are cross referenced in table 1. Thirteen studies were conducted in US samples, nine in the UK, two in the Netherlands and one in Finland.

\section{Methodological issues in studying neighbourhood social factors}

DEFINING AND MEASURING "NEIGHBOURHOOD"

All but two ${ }^{24} 25$ of the studies used geographical boundaries, developed for the census or other political purposes, as proxies for actual communities or neighbourhoods (table 1). The choice of political boundaries permits straightforward linkage with routinely collected area level data, an appropriate choice in the early stage of investigation of aetiological hypotheses; however these units may be inappropriate if they do not correspond to the actual geographical distribution of the causal factors linking social environment to health. If, for example, social support is hypothesised to be a key mechanism then the interest might be in whether or not residents receive social support within the area they define as their neighbourhood, ${ }^{6}$ whereas if access to health care were considered more important, catchment areas for local health service providers would be preferred. Instead political boundaries provide very "rough ecological profiles". ${ }^{26}$ These considerations also affect the choice of area size to use. Debate has focused on the best choice of area size when area level measures are to be used as proxies for individual measures, however, the choice of area size in contextual studies is also deserving of thoughtful consideration. ${ }^{27-30}$

Much of the discussion of the most appropriate geographical sub-unit for measuring neighbourhood social factors variables has focused on homogeneity within areas. ${ }^{31-33}$ A neighbourhood need not be homogenous to affect the lives of its inhabitants. In fact, complete homogeneity within an area precludes the study of contextual effects altogether. Extreme heterogeneity may render measures of the impact of neighbourhood averages, such as median household income, meaningless; indeed a current discussion on the health effects of income inequality suggests that both the average and the spread of neighbourhood social factors are worthy of examination. ${ }^{34}$

CHOICE OF AREA LEVEL SOCIAL VARIABLES Neighbourhood level variables are either derived from individual level variables, such as median household income, or integral to the neighbourhood and only measurable at that level, ${ }^{6}{ }^{35}$ such as number of recreational facilities. ${ }^{8}$ Only two of the studies included integral variables: level of services ${ }^{36}$ and number of community groups. ${ }^{37}$ The accessibility of census data may explain the paucity of research on integral variables. Diez-Roux has noted that derived variables are assumed to represent integral effects, ${ }^{6}$ while Macintyre et al argue that studies should focus directly on the integral economic, cultural and political characteristics of neighbourhoods. ${ }^{8}$

Several composite indices have been developed to handle highly correlated neighbourhood level variables. The advantages of such indices include statistical efficiency and a simple presentation of results. Using many single measures separately may lead to collinearity and cumbersome or cluttered results, especially when the intention is to reflect a single underlying concept such as neighbourhood socioeconomic status, rather than examining the unique contribution of each component. However, indices also have drawbacks: they are difficult to construct and validate, ${ }^{38} 39$ and tend to mask variation - that is, two areas with the same score may differ in the values that contributed to that score. Indices have limited external validity or utility across time $^{40}$ and space $^{41}$ and, depending on their component variables and weights, may measure certain aspects of neighbourhoods, for example, structural deprivation, better than others.

In the US, census variables used in contextual analyses have been derived from the decennial censuses. Population counts and basic demographic variables such as age, race and gender are obtained for all residents, while a one in six sample provides further detail on employment, income, and education. ${ }^{42}$

CONTROLLING FOR INDIVIDUAL LEVEL SOCIOECONOMIC STATUS

To understand the role of the social environment in relation to health, neighbourhood socioeconomic factors and individual socioeconomic status must be considered, as 


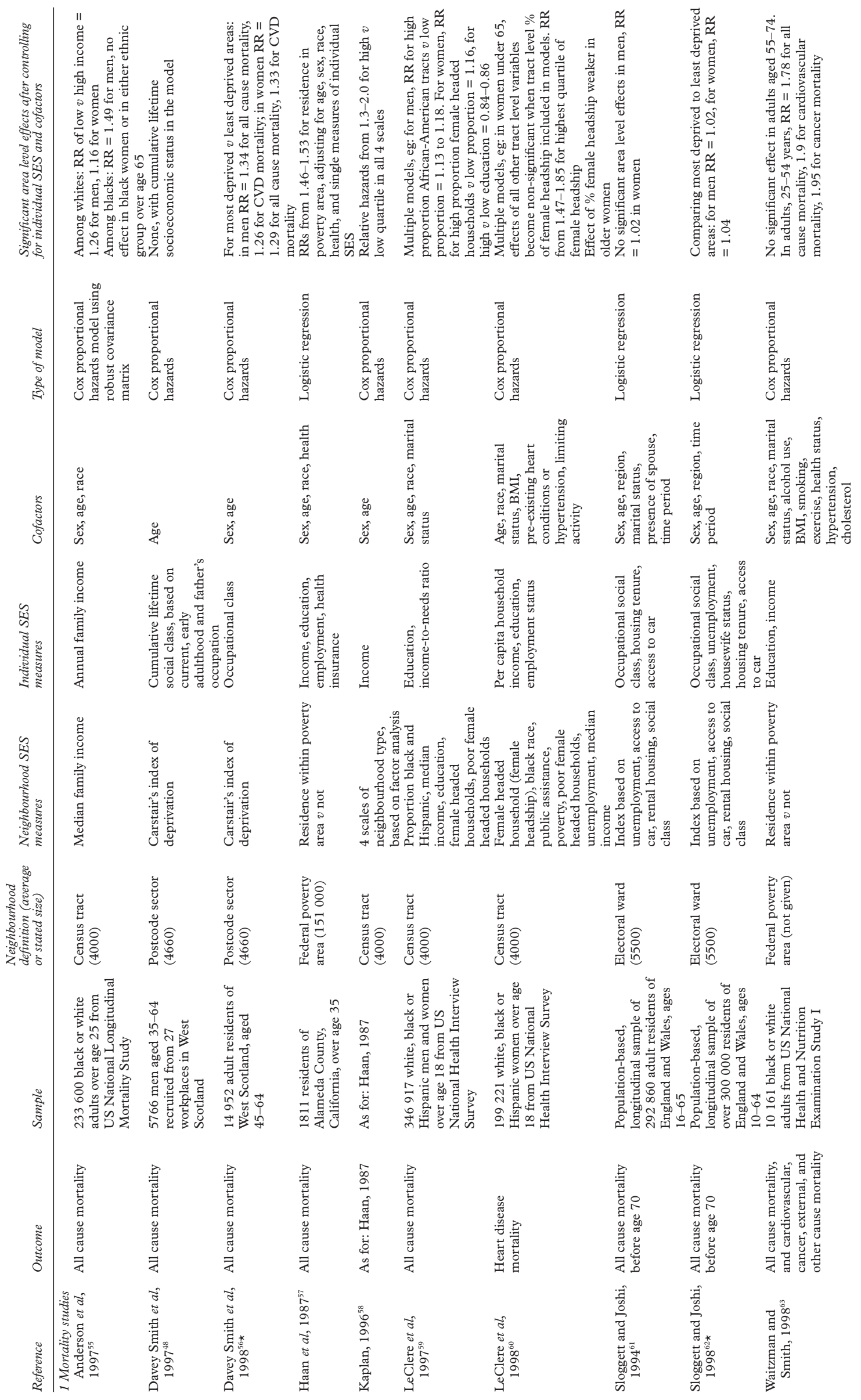




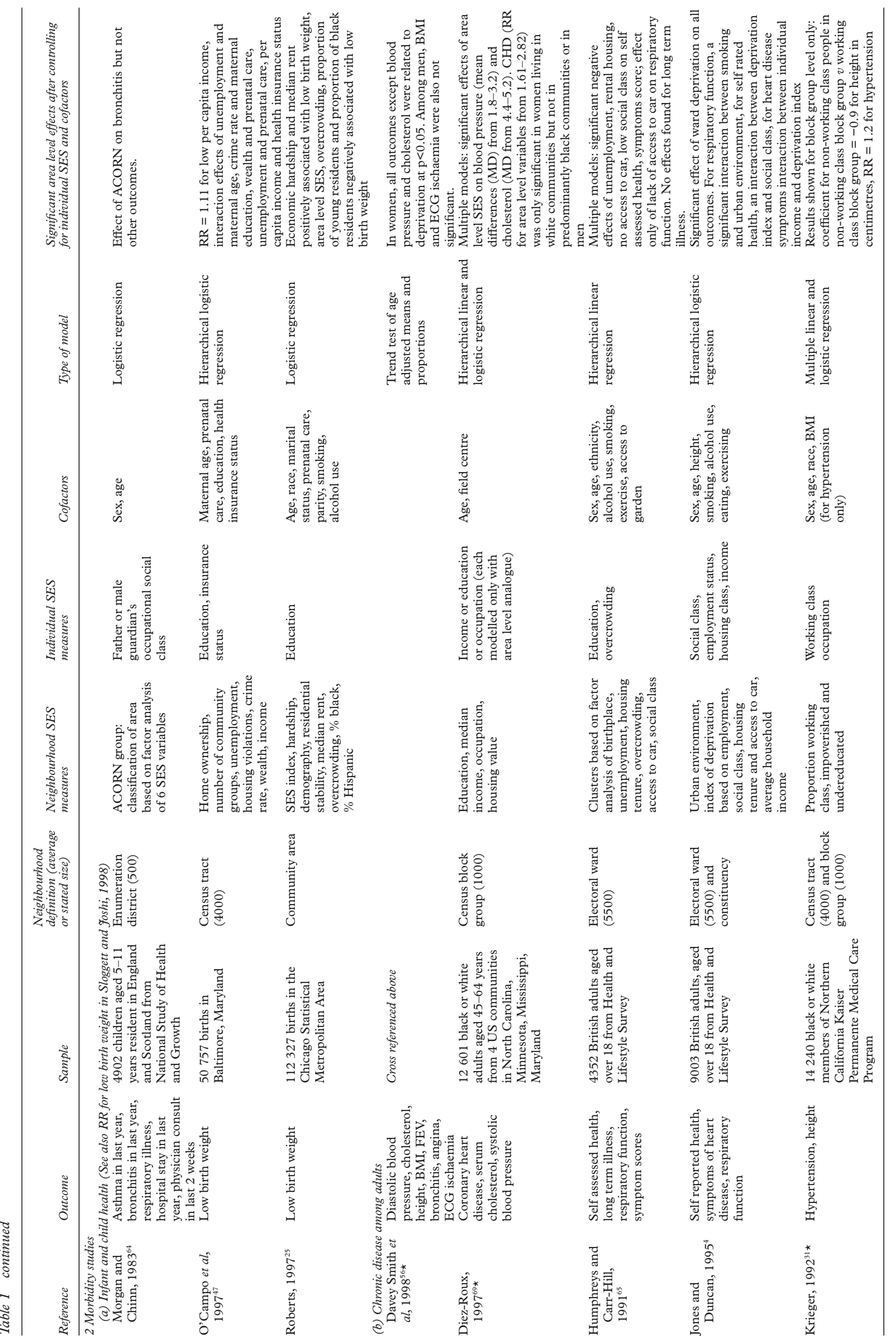




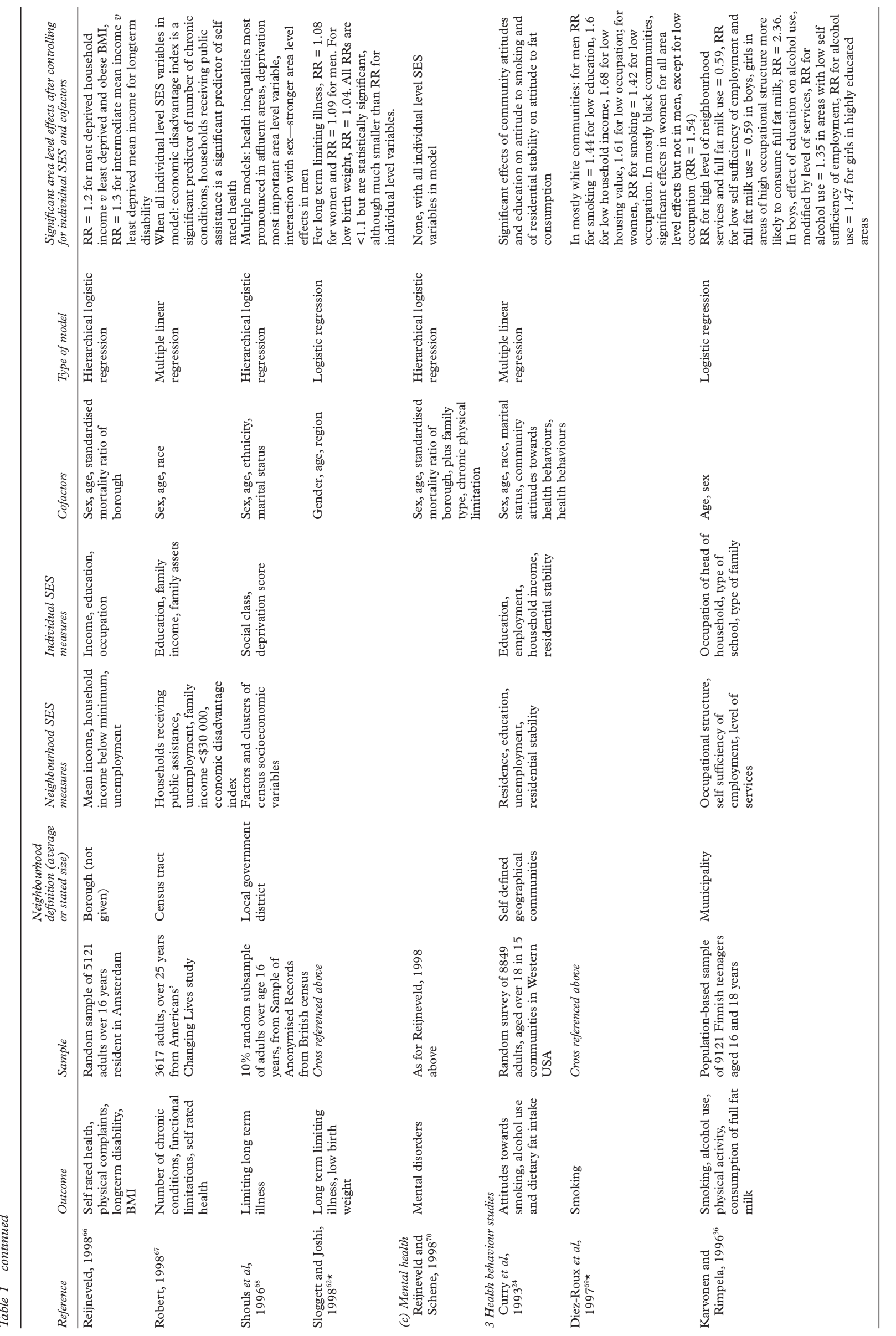




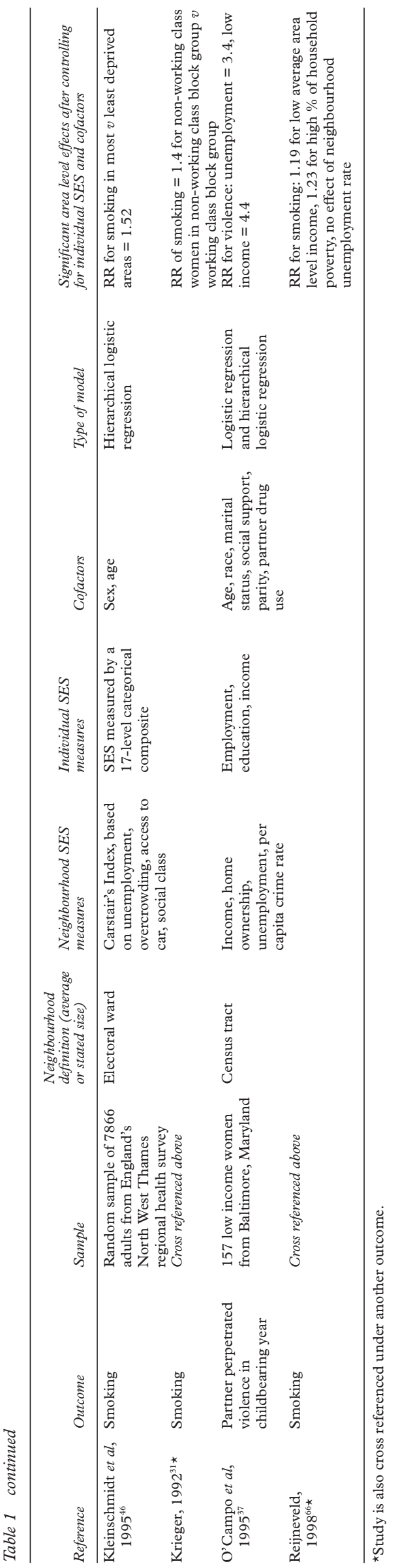

omitting either will result in incomplete model bias. Without individual level information, neighbourhood level variables may act partially or entirely as proxies for individual attributes and a partition of the contribution of each to the chosen health outcome is impossible. Without neighbourhood level measures, the impact of individual characteristics may be misunderstood.

Measurements of socioeconomic status are not routine in the US, despite widespread acceptance of the importance of these concepts as determinants of health. ${ }^{43}$ Consequently, the choice of socioeconomic variables in data collection efforts is driven by convenience rather than theory. In the UK, occupational classification of social class is measured routinely, most frequently by the British Registrar General's Scale, and there is general agreement that the scale captures some aspects of relative social position or class. The most commonly used indicators of socioeconomic status in the US are education, occupation and income, and the relation of each of these to social class is a matter of some debate. ${ }^{44}{ }^{45}$ One consensus that emerges from the literature is that all three are simple measures being used as proxies for complex concepts that we intuitively understand but cannot measure with accuracy, such as social standing, access to resources, health related attitudes, etc.

In 20 of the studies reviewed, individual level social class or socioeconomic status was measured by more than one variable, although not all of these studies included more than one measure in any model. Correlation between different measures of socioeconomic status makes the use of composite indices attractive (for example the 17 level index of individual socioeconomic status used in the study by Kleinschmidt et al of smoking behaviour ${ }^{46}$ ). The disadvantages of using a composite index are identical to those discussed above for neighbourhood level composites: it becomes impossible to differentiate the independent and interactive effects of each component and valuable information can be obscured. In the study by O'Campo et al of low birth weight, the effect of neighbourhood per capita income on low birth weight is modified by individual health insurance status, and the effect of neighbourhood crime rates depends on individual education. ${ }^{47}$ These interesting interactions could not have been observed if health insurance status and education had been combined into a single index.

When only a single measure of individual socioeconomic status is used, neighbourhood variables may be more likely to act as proxies for missing individual level information.

One study measured lifetime socioeconomic status as a combination of current, early adulthood and father's occupational class. ${ }^{48}$ Interestingly, this was one of the two studies where neighbourhood effects were statistically non-significant in models adjusted for individual socioeconomic status, suggesting that neighbourhood characteristics may reflect lifetime social circumstances or that lifetime 
socioeconomic status is more strongly related to health than current circumstances.

CONTROLLING POTENTIAL CONFOUNDING

FACTORS

In studies of neighbourhood social factors and health outcomes, it is important for researchers to conceptualise the causal pathways by which they believe neighbourhood characteristics affect health. If causal pathways are believed to involve neighbourhood associated differences in health behaviours, such as smoking, then such behaviours are not potential confounding variables to be controlled, but component causes of a pathway that need to be explored. ${ }^{49}{ }^{50}$ As much of the literature on neighbourhood social factors and health outcomes is exploratory in nature, a variety of approaches towards adjusting for confounding factors have been taken, and the causal pathways that underlie hypotheses about the effects of neighbourhood social factors are often not explicit.

When both a risk factor and a confounding factor are measured with error, the unmeasured variation in the confounding variable can "resonate" and cause residual confounding with unpredictable effects on estimates of relative risk, unless the strength and direction of the correlation between risk factor and confounder are known. ${ }^{51}$ It is probable that measurements of both neighbourhood and individual socioeconomic status contain error, and that risk estimates for neighbourhood level social factors are affected by residual confounding from measurement error of individual level socioeconomic status.

CHOICE OF ANALYTIC MODEL

Many of the multilevel studies we reviewed used single level linear and logistic regression analysis and Cox proportional hazards models to estimate the impact of neighbourhood factors on health. In fact, the hierarchical nature of such data, where individuals are nested within neighbourhoods, is more correctly approached with multilevel models that account for this hierarchical clustering. ${ }^{52}$ Statistical models that assume that individuals are independently sampled are unable to account for the intra-neighbourhood correlation that arises from the fact that people from the same neighbourhood will be more alike in unmeasured characteristics than people from different neighbourhoods. This violation of the independence assumption can lead to incorrect estimation of the standard errors of model parameters in non-hierarchical models and the possibility of incorrect inference concerning the effect of the neighbourhood level characteristics. Estimation techniques for hierarchical models for both discrete and continuous outcomes have been developed, and computer software to implement them is now available in standard statistical packages. ${ }^{53}$ The importance of using multilevel techniques is a matter of current debate. $^{5354}$ Ten of the 25 studies reviewed used hierarchical models of some kind, all had publications dates between 19911998 (see table 1). The other 15, with publication dates from 1983-1998, used single
KEY POINTS

- Attributing health disparities to neighbourhood social context requires the isolation of individual level socioeconomic influence.

- "Neighbourhood" has been operationally defined in various ways in studies in developed countries, but few have conformed to natural boundaries.

- Findings of significant interactions suggest that neighbourhood context may differentially affect the health of people.

level models. Although we noted an increase of hierarchical modelling with time, five studies published in 1998 used single level models. One study that presented results from both single level and multilevel analyses of the effect of neighbourhood characteristics on domestic violence provides an illustration of the potential problems that may arise from an inappropriate choice of models. ${ }^{37}$ The odds ratios (and 95\% confidence intervals) for risk of domestic violence according to residence in a low income neighbourhood were $4.4(1.1,18.2)$ in a hierarchical model, and $4.9(0.36,66.7)$ in a single level model. There is little change in the estimate of effect but sufficient change in the estimate of the standard error to affect significance tests.

\section{Results}

Results of the 25 studies are presented in the last column of table 1 . The studies are grouped by the health outcome of interest to allow for easier comparison.

\section{MORTALITY STUDIES}

Ten studies investigated the effects of neighbourhood social factors on mortality, ${ }^{48} 55-63$ although two of the studies were analyses of the same sample, ${ }^{57}{ }^{58}$ one study ${ }^{60}$ was conducted on a subset of another, ${ }^{59}$ and one study ${ }^{62}$ was a longer follow up of a previously analysed cohort. ${ }^{61}$ All of the studies focused on all cause mortality (sometimes with separate analyses of cause specific mortality) in both men and women, except for one that examined mortality attributable to heart disease in women. ${ }^{60}$ Neighbourhood effects are fairly consistent across studies, with modest (RR less than 2.0) but statistically significant increased risk of mortality in poorer or more deprived neighbourhoods. In contrast, Davey Smith and colleagues found effects of neighbourhood deprivation within categories of lifetime socioeconomic status, but the overall effect of neighbourhood deprivation was not significant. ${ }^{48}$ Sloggett and Joshi found essentially no role for neighbourhood factors in a large cohort with nine years of follow up, with no significant area level effects in men and a significant relative risk of only 1.02 in women. ${ }^{61}$ However, after 13 years of follow up, significant neighbourhood effects were found in both men and women. ${ }^{62}$

Three of these studies found the effect of neighbourhood to be modified by age $e^{556063}$; in all three there was less impact of neighbourhood 
factors in older age groups, suggesting that other factors related to survival may be more important in older age groups. Haan et al and Kaplan report separate analyses of the same sample. ${ }^{5758}$ The greater magnitude of the neighbourhood effect in Kaplan's study may be attributable to the finer scale of the defined neighbourhoods (census tracts versus federal poverty area)

Only one of the mortality studies used an analytic model that accounted for the hierarchical structure of the data, and its results are consistent with the overall finding of modestly increased mortality risk. ${ }^{55}$

\section{MORBIDITY STUDIES}

Infant and child health

The three studies that examined infant birth weight all found significant neighbourhood effects, ${ }^{25} 4762$ but in all three the effect was modest (RR less than 2.0). Neighbourhoods with a high percentage of black residents were found to protect against low birth weight in one study, ${ }^{25}$ while another reported multiple interactions between characteristics of mothers and their neighbourhoods. ${ }^{47}$ For example, the association of prenatal care with reduced incidence of low birth weight was stronger in areas with low unemployment, compared with areas with high unemployment, which suggests that prenatal care is less protective for women living in deprived neighbourhoods. In the only study of childhood illness, Morgan and Chinn showed that ACORN group, a classification system for neighbourhood characteristics, was associated with bronchitis in the previous 12 months, but asthma, all respiratory illnesses, doctor visits and hospital stays were not. ${ }^{64}$

\section{Chronic disease among adults}

Ten studies investigated morbidity in adults, including self rated health, ${ }^{46566}$ long term disability or illness, ${ }^{62}{ }^{65-68}$ cardiovascular risk factors, symptoms or disease, ${ }^{4315669}$ and respiratory function or illness. ${ }^{4665}$ Most studies investigated multiple chronic conditions and outcomes in order to capture a general concept of adult health, whereas others focused on particular outcomes (see for example studies $^{316869}$ ).

Three of four studies on self rated health found significant neighbourhood effects. ${ }^{465} 67$ Reijneveld found no significant neighbourhood effects on self rated poor health after adjustment of income, education and occupation. ${ }^{66}$ However, this study and the same author's study of mental health (see below) may have lacked statistical power.

Three studies found no significant neighbourhood effects on long term illness ${ }^{65}$ functional limitations, ${ }^{67}$ and long term physical limitations. ${ }^{66}$ Robert did find an effect of neighbourhood economic disadvantage (a composite index) on number of chronic diseases but no single neighbourhood variable had a significant effect. ${ }^{67}$ Shouls et al reported that neighbourhood deprivation was associated with increased risk of long term illness, and that the neighbourhood effect was stronger for men than women. ${ }^{68}$ Small but significant neighbourhood effects on long term limiting illness were reported in a more recent study from the UK. ${ }^{62}$

Among the studies of coronary heart disease and its risk factors, Diez-Roux et al found neighbourhood effects on systolic blood pressure and serum cholesterol in all areas studied, but for heart disease only among women living in predominantly white areas. ${ }^{69}$ Neighbourhood deprivation scores were associated with increased body mass index and prevalence of angina and ischaemia among women, and increased prevalence of angina among men in a study population in Scotland. ${ }^{56}$ Jones and Duncan found increased reporting of heart disease symptoms as neighbourhood deprivation increased among low and middle income adults, but the opposite among adults with high incomes. ${ }^{4}$ Neighbourhood effects on hypertension among non-working class subjects were reported by Krieger. ${ }^{31}$

All three studies of adult respiratory function reported at least one significant area level effect. Humphreys and Carr-Hill studied five neighbourhood characteristics and found that only the percentage of people not owning a car was a significant predictor. ${ }^{65}$ Jones and Duncan found that urban neighbourhoods were associated with poor respiratory functioning among non-smokers, while smokers had poor functioning regardless of neighbourhood urbanity. ${ }^{4}$ Davey Smith et al showed significant trend tests for increasing neighbourhood deprivation and respiratory function and bronchitis. ${ }^{56}$

\section{Studies of mental health}

Only one study focused on mental health as an outcome. ${ }^{70}$ No significant neighbourhood effect persisted after adjustment for family size, occupation, and education. This study may have suffered from insufficient statistical power for two reasons: (1) there were only 22 neighbourhoods (boroughs), limiting the ability to detect between group differences ${ }^{17}$; and (2) the boroughs may have been too homogenous, creating collinearity between individual and neighbourhood SES measures.

STUDIES OF HEALTH BEHAVIOURS

Seven studies investigated the effects of neighbourhood social factors on health behaviours or attitudes. ${ }^{24313637466669}$ Five of these studies looked at smoking behaviour as a primary outcome, ${ }^{3136466669}$ one also examined alcohol and dietary intake, ${ }^{36}$ and one examined individual attitudes towards smoking, alcohol use and dietary intake, rather than the behaviours themselves. ${ }^{24}$ One study looked at reproductive health behaviours, ${ }^{31}$ and one study focused on domestic violence. ${ }^{37}$

Four of the five papers that assessed the effects of neighbourhood social factors on smoking reported increased relative risks (RR) of smoking between $1.2-1.7$ in neighbourhoods with low socioeconomic status. ${ }^{31466669}$ The study by Karvonen and Rimpela in a Finnish population reported no significant relations between neighbourhood and smoking, ${ }^{36}$ however this study focused on a sample of adolescents, aged 16-18 years, whereas the 
other four studies of smoking were in adults. Diez-Roux et al found that the effect of neighbourhood social factors on smoking was modified by both gender and race. ${ }^{69}$

Karvonen and Rimpela report several modest interactions between neighbourhood socioeconomic status and gender in relation to adolescent health behaviours, despite finding no effects for smoking. ${ }^{36}$ For example, the relative risk for alcohol use was 1.35 among boys living in areas with low employment status compared with boys living in areas with better employment status, whereas the relative risk for alcohol use was 1.47 among girls living in areas with high education status compared with areas with low education status. Further interactions between neighbourhood factors and school type were reported, as well as equally complex results for the use of full fat milk products.

Curry et al studied attitudes towards health behaviours, hypothesising that neighbourhood socioeconomic status, as well as the prevalence of health behaviours, will be related to social tolerance and normative attitudes towards health related behaviours. ${ }^{24}$ Indeed, they found neighbourhood effects on attitudes towards smoking and dietary fat consumption, but not on attitudes towards alcohol consumption.

O'Campo and colleagues studied male partner violence towards women during the childbearing year and report the largest magnitude of neighbourhood effects of all the studies we identified, a relative risk of violence of 3.42 for high neighbourhood unemployment and of 4.4 for low neighbourhood income. ${ }^{37}$ These greater magnitudes may be attributable to the more direct pathways that can be hypothesised to lead from stressful neighbourhood contexts towards violent behaviour, than can be conjectured for other health outcomes.

\section{Discussion}

We have reviewed multilevel studies of neighbourhood socioeconomic context and health. In 23 of the 25 studies we identified, researchers reported a statistically significant association between at least one neighbourhood measure of socioeconomic status and health, controlling for individual socioeconomic status. The studies that found no association included the only study of mental health ${ }^{70}$ and the only study to measure lifetime rather than current individual socioeconomic status. ${ }^{48} \mathrm{De}-$ spite this apparent consistency across studies, a detailed appraisal of this literature suggests a more complicated picture.

An inclusion criterion for this review was adjustment for individual level socioeconomic status. However, some studies adjusted for only one measure of individual socioeconomic status, whereas others adjusted for two or more. Without adequate control of individual socioeconomic status, neighbourhood level effects may act as proxies for unmeasured aspects of individual socioeconomic status. ${ }^{27}$ Reijneveld's study of mental disorders illustrates the effects of controlling for multiple measures of individual socioeconomic status. ${ }^{70}$ In models adjusting for individual level educa- tion or occupation, a statistically significant association was demonstrated between low neighbourhood income and increased prevalence of mental disorders. However, when individual level income was added to these models, there was no statistically significant neighbourhood level effect. In general, studies adjusting for more than one individual level measure of socioeconomic status found smaller measures of association between neighbourhood level socioeconomic status and health. For example, Sloggett and Joshi's study found a much weaker association of neighbourhood socioeconomic status with all cause mortality, adjusting for three measures of individual level socioeconomic status, ${ }^{61}$ than the analyses of Haan et al's of the same association, ${ }^{57}$ each of which were adjusted for only one measure of individual level socioeconomic status. On the other hand, the extent that neighbourhood socioeconomic status determines individual income, education, and occupation, controlling for individual socioeconomic status may remove part of the contextual effect.

We grouped studies by type of outcome, as presented in table 1, to allow for easier comparison of similar studies. However, as this literature is still fairly sparse, there are not enough replication studies using the same health outcomes, covariates, exposures and study designs to allow for more than a preliminary guess of the magnitude of neighbourhood effects for particular health outcomes. Domestic violence during the childbearing year showed the strongest association with neighbourhood socioeconomic context. ${ }^{37}$ In general, risk ratios for low neighbourhood socioeconomic status and negative health behaviours were consistent and modest, as were those for mortality, but the impact of neighbourhood characteristics on morbidity was more variable; evidence for long term illness and disability was weak, while evidence for respiratory function in adults was stronger.

It is possible, and even plausible, that some characteristics of neighbourhoods may be more or less related to health outcomes than others, although many characteristics of neighbourhoods are highly correlated. For instance average neighbourhood income might be a better predictor of health status than the proportion of households suffering from overcrowding. The level at which variables are measured may also be important, for example, poverty at the census block group level might be more strongly associated with health than poverty at the county level. In the studies we review, it is difficult to compare the impact of different neighbourhood characteristics or definitions because of the heterogeneity in study designs. Studies that used indices of several neighbourhood socioeconomic characteristics to rank neighbourhoods on a single dimension (usually poverty or deprivation) and those that used factor analysis to identify clusters of neighbourhood characteristics do not permit discrimination between the effects of different neighbourhood characteristics.

In studies with only a single individual level SES variable, the neighbourhood level SES 
variables may be capturing unmeasured individual level variation in outcome, ${ }^{27}$ however we do not believe that models that include only one measure of neighbourhood level socioeconomic status are equally suspect. Neighbourhood level socioeconomic characteristics are much more highly correlated than individual level socioeconomic factors, so that misspecifying the neighbourhood level effect is less likely to occur. The choice of neighbourhood level variables may be less critical than ensuring proper control for individual level socioeconomic status.

Neighbourhood socioeconomic context might affect health either directly, if simply living in a deprived neighbourhood is deleterious to health, ${ }^{7}$ or indirectly through such mechanisms as the availability and accessibility of health services, healthy foods or recreational facilities, environmental pollution, normative attitudes towards health, and social support. ${ }^{617}$ Measures of neighbourhood socioeconomic status can therefore be viewed as both proxies for unmeasured mechanisms or as actual exposures in their own right, or both.

It is therefore important for researchers to begin to be explicit about the causal pathways they believe to be operating between neighbourhood socioeconomic context and health, and to consider how adjustment for factors on the causal pathway may bias estimates of neighbourhood factors. For example, adjusting for smoking, which may be a consequence of living in a deprived neighbourhood, as well as a cause of poor respiratory function, may weaken the association between neighbourhood and health outcome. On the other hand, researchers may be interested in how the association between smoking and respiratory function is modified by neighbourhood characteristics. Most of the studies we reviewed were exploratory in nature and did not specify the causal mechanisms linking the factors included in their multivariate analyses, but this is clearly an important next step for understanding the relation between neighbourhood and health.

British studies of neighbourhood effects stem from a larger movement examining social inequalities and health that includes studies of income inequality, regional and rural-urban variation in health and social gradient research (see, for example, references ${ }^{3} 1033$ 65 71-74). Proponents and critics of this kind of research tend to be divided along sharply political lines. In the US, concern for social justice may be the motivation for some of this research but debate concerning its implications has not reached the political arena with any force. Epidemiologists and others in public health often feel that identifying social determinants of health may be fruitless if the ability to change social structures and inequalities lies outside of the public health domain. While these studies may provide ammunition for political debate and draw attention to inequities in health, they also serve the purpose of identifying types of geographical areas where traditional public health interventions, aimed at individual risk reduction, may best be targeted and providing impetus for new interventions when interesting associations are discovered.

In the studies we review, relative risks are typically modest. However, the population attributable risk of living in neighbourhoods with low socioeconomic status is likely to be high, as such conditions are extremely prevalent.

A potential problem with these studies is that their statistical power and findings depend on there being people within each neighbourhood who are not typical of the neighbourhood, as heterogeneity is needed to distinguish between individual level and neighbourhood level effects. In other words, these studies are driven by "fish out of water"-people who may be uncharacteristic of the neighbourhood in which they live in ways that researchers do not measure. Therefore, factors that may be associated with being atypical might explain apparent neighbourhood effects.

In addition, results derived from these small numbers of atypical residents may generalise to a small population group. For instance, Roberts found that while being black increased a woman's individual risk of having a low birthweight infant, living in a predominantly black neighbourhood was associated with a decreased risk. ${ }^{25}$ This means that black women living in predominantly white neighbourhoods are particularly vulnerable. However, because more black women will live in predominantly black neighbourhoods than in predominantly white neighbourhoods, focusing prevention and policy efforts on the small number of atypical women would be inefficient. Attention to the prevalence of the exposure, as well as relative risks, will ensure that preventive efforts and public health policy will focus on those population sub-groups and geographical areas where most benefit can be expected.

It is clear from our review that investigations of the role of neighbourhood level social factors on health are characteristic of preliminary, exploratory studies in epidemiology. Certain aspects of study design are in need of improvement before the field can advance. Firstly, definitions of neighbourhood need to reflect actual neighbourhood boundaries more accurately. Secondly, careful delineation of theorised causal pathways will lead to more precise definition and measurement of factors at the neighbourhood level that will allow tests of causal hypotheses. Qualitative information, such as that collected in sociological and ethnographic research, can inform and guide this process. Thirdly, if multilevel analyses of neighbourhood level effects are to provide useful information to guide public health policy and preventive programmes, data measuring important factors in real neighbourhoods need to be routinely collected and linked to health outcome data. As an example of what can be achieved in this manner, the city of Chicago has defined and collected information on community areas since the 1920 s, giving rise to a rich tradition of inquiry into the relations between neighbourhood factors and social outcomes (see for example, Sampson et $a l^{75}$ ). When defined neighbourhoods are "ecologically 
meaningful", constructs of social context are theoretically based and examined for construct validity, and competing hypotheses are explicitly defined and tested, we will better understand the effect of neighbourhood context on health. We hope that this review will show what has already been achieved and point the way to more sophisticated studies of societal determinants of health.

We would like to thank Dr William Satariano, Dr Warren Winkelstein, Dr Ralph Catalano, Dr Barbara Abrams, Dr Steve Selvin and Dr Irene Yen for encouragement and discussions, as well as the helpful insights of our reviewers.

Funding: this work was supported by a grant from the California Wellness Foundation.

Conflicts of interest: none.

1 Adler NE, Boyce T, Chesney MA, et al. Socioeconomic status and health: the challenge of the gradient. Am Psychol tus and health:

2 Krieger N, Fee E. Man-made medicine and women's health: the biopolitics of sex/gender and race/ethnicity. Int $\mathcal{F}$ Health the biopolitics of sex/g
Serv $1994 ; 24: 265-83$.

3 Macintyre S. Understanding the social patterning of health: the role of the social sciences. F Public Health Med 1994;16 53-9.

4 Jones K, Duncan C. Individuals and their ecologies: analysing the geography of chronic illness within a multileve modelling framework. Health and Place 1995;1:27-40.

5 Cassel J. The contribution of the social environment to host resistance. Am f Epidemiol 1976;104:107-23.

6 Diez-Roux A. Bringing context back into epidemiology: variables and fallacies in multi-level analysis. Am $\mathcal{f}$ Public Health 1998;88:216-22.

7 Krieger N, Rowley D, Herman A, et al. Racism, sexism and social class: implications for studies of health, disease and well-being. Am f Prev Med 1993;9 (suppl 2):82-122.

8 Macintyre S, Maciver S, Sooman A. Area, class and health: Should we be focusing on places or people? fournal of Social Phould we be focusing o

9 Susser M, Susser E. Choosing a future for epidemiology: II. From black box to Chinese boxes and eco-epidemiology. Am f Public Health 1996;86:674-7.

10 Townsend P. Individual or social responsibility for premature death? Current controversies in the British debate about health. Int f Health Serv 1990;20:373-92.

11 Yen IH, Syme SL. The social environment and health: a discussion of the epidemiologic literature. Anпи Rev Public Health 1999;20:287-308.

12 Winkelstein W. Epidemiological considerations underlying the allocation of health and disease care resources. Int $\mathcal{F}$ Epidemiol 1972;1:69-74.

13 Jencks C, Mayer SE. The social consequences of growing up in a poor neighborhood. In: Jr LL, McGeary M, eds. Inner city poverty in the US. Washington: National Academy city poverty in the

14 Jencks C, Mayer SE. Residential segregation, job proximity, and black job opportunities. In: Jr LL, McGeary M, eds. Inner city poverty in the
Press, 1990:187-222.

15 Corcoran M, Gordon R, Laren D, et al. Poverty and the underclass: effects of family and community background on economic status. American Ecology Review 1990;80:3626.

16 Susser M, Susser E. Choosing a future for epidemiology: I. Eras and paradigms. Am ₹ Public Health 1996;86:668-73.

17 Duncan C, Jones K, Moon G. Context, composition and heterogeneity: using multilevel models in health research. Soc Sci Med 1998;46:97-117.

18 Brewster KL. Neighborhood context and the transition to sexual activity among young black women. Demography 1994;31:603-14.

19 Grady WR, Klepinger DH, Billy JO. The influence of community characteristics on the practice of effective contramunity characteristics on the practice of
ception. Fam Plann Perspect 1993;25:4-11.

20 Wilkinson RG. Income inequality, social cohesion, and health: clarifying the theory-a reply to Muntaner and health: clarifying the theory - a reply to
Lynch. Int $\mathcal{F}$ Health Serv 1999;29:525-43.

21 Kaplan GA, Pamuk ER, Lynch JW, et al. Inequality in income and mortality in the United States: analysis of mor tality and potential pathways. BMF 1996;312:999-1003.

22 Kawachi I, Kennedy BP, Lochner K, et al. Social capital, income inequality, and mortality. Am F Public Health 1997; 87:1491-8.

23 Collins JW, Jr., Herman AA, David RJ. Very-lowbirthweight infants and income incongruity among African American and white parents in Chicago. Am $\mathcal{F}$ Public Health 1997;87:414-17.

24 Curry SJ, Wagner EH, Cheadle A, et al. Assessment of community-level influences on individual's attitudes about cigarette smoking, alcohol use, and consumption of dietary fat. Am F Prev Med 1993; 9:78-84.

25 Roberts E. Neighborhood social environments and the distribution of low birthweight in Chicago. Am $\mathcal{F}$ Public Health 1997;87:597-603.
26 Foley DL. Census tracts and urban research. Fournal of the American Statistical Association 1953;48:733-42.

27 Geronimus A, Bound J, Neidert L. On the validity of using census geocode characteristics to proxy individual socioeconomic characteristics. Fournal of the American Statistical Association 1996;91:529-37.

28 Geronimus AT, Bound J. Use of census-based aggregate variables to proxy for socioeconomic group: evidence from national samples. Am f Epidemiol 1998;148:475-86.

29 Krieger N, Gordon D. Re: "Use of census-based aggregate variables to proxy for socioeconomic group: evidence from national samples". Am f Epidemiol 1999;150:892-6.

30 Davey Smith G, Hart C. Re: "Use of census-based aggregate variables to proxy for socioeconomic group: evidence from national samples". Am $\mathcal{F}$ Epidemiol 1999;150:996-7.

31 Krieger N. Overcoming the absence of socioeconomic data in medical records: validation and application of a censusbased methodology. Am f Public Health 1992;82:703-10.

32 Myers JK. Note on the homogeneity of census tracts: a methodological problem in urban ecological research. Social Forces 1954;32:364-6.

33 Townsend P, Phillimore P, Beattie A. Health and deprivation: inequality and the North. London: Croom Helm, 1988.

34 Kawachi I, Kennedy BP. Income inequality and health: pathways and mechanisms. Health Serv Res 1999;34:215-27.

35 Von Korff M, Koepsell T, Curry S, et al. Multi-level analysis in epidemiologic research on health behaviors and outcomes. Am F Epidemiol 1992;135:1077-82.

36 Karvonen S, Rimpela A. Socio-regional context as a determinant of adolescents' health in Finland. Soc Sci Med 1996;43:1467-74.

37 O'Campo P, Gielen A, Faden R, et al. Violence by male partners against women during the childbearing year: a contextual analysis. Am f Public Health 1995;85:1092-7.

38 Gilthorpe MS. The importance of normalisation in the construction of deprivation indices. 7 Epidemiol Community Health 1995;49 (suppl 2):S45-50.

39 Gordon D. Census based deprivation indices: their weighting and validation. $\mathcal{F}$ Epidemiol Community Health 1995;49 (suppl 2):S39-44.

40 Dolan SA, Jarman B, Bajjekal $\mathrm{M}$, et al. Measuring disadvantage: changes in the underprivileged area, Townsend, and Carstairs scores 1981-91. F Epidemiol Community Health 1995;49 (suppl 2):S30-3.

41 Talbot RJ. Underprivileged areas and health care planning: implications of use of Jarman indicators of urban deprivation. BMF 1991;302:383-6.

42 Census Bureau. Census of population and housing. Summary Tape File 3 on CD-ROM Technical Documentation. Washington, DC: Census Bureau, 1992.

43 Krieger N, Fee E. Social class: the missing link in US health data. Int f Health Serv 1994;24:25-44.

44 Liberatos P, Link BG, Kelsey JL. The measurement of social class in epidemiology. Epidemiol Rev 1988;10:87-121.

45 Krieger N, Williams DR, Moss NE. Measuring social class in US public health research: concepts, methodologies, an guidelines. Annu Rev Public Health 1997;18:341-78.

46 Kleinschmidt I, Hills M, Elliott P. Smoking behaviour can be predicted by neighbourhood deprivation measures. $f$ Epidemiol Community Health 1995;49 (suppl 2):S72-7. 47 O'Campo P, Xue X, Wang M-C, et al. Neighborhood risk
factors for low birthweight in Baltimore: a multilevel analysis. Am f Public Health 1997;87:1113-18.

48 Davey Smith G, Hart C, Blane D, et al. Lifetime socioeconomic position and mortality: prospective observational study. BMf 1997;314:547-52.

49 Weinberg C. Toward a clearer definition of confounding. Am F Epidemiol 1993;137:1-8.

50 Rothman KJ, Greenland S. Modern epidemiology. 2nd ed. Philadelphia: Lippincott-Raven Publishers, 1998.

51 Marshall JR, Hastrup JL. Mismeasurement and the resonance of strong confounders: uncorrelated errors. $A m \mathcal{F}$ Epidemiol 1996;143:1069-78.

52 Kreft I, De Leeuw J. Introducing multilevel modeling. Thousand Oaks, CA: Sage Publications, 1998

53 de Leeuw J, Kreft I. Questioning multi-level models. fournal of Educational and Behavioral Statistics 1995;20:171-89.

54 Draper D. Inference and hierarchical modeling in the social sciences. F Educational and Behavioral Statistics 1995;20: 115-47.

55 Anderson R, Sorlie P, Backlund E, et al. Mortality effects of community economic status. Epidemiology 1997;8:42-7.

56 Davye Smith G, Hart C, Watt G, et al. Individual social class, area-based deprivation, cardiovascular disease risk factors, and mortality: the Renfrew and Paisley study. $\mathcal{F}$ Epidemiol Community Health 1998;52:399-405.

57 Haan M, Kaplan GA, Camacho T. Poverty and health: prospective evidence from the Alameda County Study. Am $\mathcal{F}$

58 Kaplan G. People and places: contrasting perspectives on the association between social class and health. Int $\mathcal{F}$ Health Serv 1996;26:507-19.

59 LeClere F, Rogers R, Peters K. Ethnicity and mortality in the United States: individual and community correlates. Social Forces 1997;76:169-98.

60 Leclere F, Rogers R, Peters K. Neighborhood social context and racial differences in women's heart disease mortality. $\mathcal{f}$ Health Soc Behav 1998;39:91-107.

61 Sloggett A, Joshi H. Higher mortality in deprived areas: community or personal disadvantage? BMF 1994;309: $1470-4$

62 Sloggett A, Joshi H. Deprivation indicators as predictors of life events 1981-1992 based on the UK ONS Longitudin Study. F Epidemiol Community Health 1998;52:228-33. 
63 Waitzman N, Smith K. Phantom of the area: poverty-area residence and mortality in the United States. Am $\mathcal{F}$ Public Health 1998;88:973-6.

64 Morgan M, Chinn S. ACORN group, social class, and child health. Am f Epidemiol 1983;37:196-203.

65 Humphreys K, Carr-Hill R Area variations in health outcomes: artefact or ecology. Int f Epidemiol 1991;20:251-8. 66 Reijneveld S. The impact of individual and area characteristics on urban socioeconomic differences in health and smoking. Int $\mathcal{F}$ Epidemiol 1998;27:33-40.

67 Robert S. Community-level socioeconomic status effects on adult health. F Health Soc Behav 1998;39:18-37.

68 Shouls S, Congdon P, Curtis S. Modelling inequality in reported long-term illness in the UK: combining individual and area characteristics. $f$ Epidemiol Community Health 1996;50:366-76.

69 Diez-Roux A, Nieto F, Muntaner C, et al. Neighborhood environments and coronary heart disease: a multilevel analysis. Am f Epidemiol 1997;146:48-63.
70 Reijneveld S, Schene A. Higher prevalence of mental disorders in socioeconomically deprived urban areas in the Netherlands: community or personal disadvantage? $f$ Epidemiol Community Health 1998;52:2-7.

71 Carstairs V. Deprivation indices: their interpretation and use in relation to health. F Epidemiol Community Health 1995;49 (suppl 2):S3-8.

72 Folwell K. Single measures of deprivation. $\mathcal{F}$ Epidemiol Community Health 1995;49 (suppl 2):S51-6.

73 Phillimore P, Beattie A, Townsend P. Widening inequality of health in northern England, 1981-91. BMF 1994;308: $1125-8$

74 Townsend P. Widening inequalities of health in Britain: a rejoinder to Rudoph Klein. Int f Health Serv 1990;20:36372 .

75 Sampson R, Raudenbush S, Earls F. Neighborhoods and violent crime: a multilevel study of collective efficacy. Science 1997;277:918-24. 